\title{
Formation of ice supersaturation by mesoscale gravity waves
}

\author{
P. Spichtinger, K. Gierens, and A. Dörnbrack \\ Deutsches Zentrum für Luft- und Raumfahrt, Institut für Physik der Atmosphäre, Oberpfaffenhofen, Germany \\ Received: 4 October 2004 - Published in Atmos. Chem. Phys. Discuss.: 10 January 2005 \\ Revised: 10 March 2005 - Accepted: 22 March 2005 - Published: 30 May 2005
}

\begin{abstract}
.
We investigate the formation and evolution of an icesupersaturated region (ISSR) that was detected by means of an operational radiosonde sounding launched from the meteorological station of Lindenberg on 21 March 2000, 00:00 UTC. The supersaturated layer was situated below the local tropopause, between 320 and $408 \mathrm{hPa}$ altitude. Our investigation uses satellite imagery from METEOSAT and the Advanced Very High Resolution Radiometer (AVHRR) and analyses of the European Centre for Medium-Range Weather Forecasts (ECMWF). Mesoscale simulations reveal that the ISSR was formed by a temporary vertical uplift of upper tropospheric air parcels by 20 to $40 \mathrm{hPa}$ in 1 to $2 \mathrm{~h}$. This resulted in a significant local increase of the specific humidity by the moisture transport from below. The ascent was triggered by the superposition of two internal gravity waves, a mountain wave induced by flow past the Erzgebirge and Riesengebirge south of Lindenberg, and an inertial gravity wave excited by the anti-cyclonically curved jet stream over the Baltic Sea. The wave-induced ISSR was rather thick with a depth of about $2 \mathrm{~km}$. The wave-induced upward motion causing the supersaturation also triggered the formation of a cirrus cloud. METEOSAT imagery shows that the cirrus cloud got optically thick within two hours. During this period another longer lasting thin but extended cirrus existed just beneath the tropopause. The wave-induced ISSR disappeared after about half a day in accordance with the decaying wave activity.
\end{abstract}

\section{Introduction}

Ice-supersaturated regions (ISSRs) in the upper troposphere are generally colder and moister (in the sense of water vapour

Correspondence to: P. Spichtinger

(peter.spichtinger@dlr.de) concentration) than their subsaturated surroundings (Gierens et al., 1999; Spichtinger et al., 2003b). These contrasts reveal information on the probable pathways to supersaturated states. In the case of a temperature contrast to the subsaturated environment it is probably adiabatic cooling by largescale ascending motion leading to supersaturation. However, in the lowermost stratosphere and in the tropical tropopause layer diabatic cooling by radiation can be effective, too. In case of a moisture contrast, smaller scale motions transport moisture from lower levels upward leading to localised supersaturation.

In a companion paper (Spichtinger et al., 2005, hereafter Case 1) we studied the formation of ice-supersaturated regions in the cold upper troposphere over NE Germany. This ISSR was formed by adiabatic cooling in a slowly ascending airmass under the influence of a warm conveyor belt associated with a low pressure system west of Ireland. In this paper, we present a different case where supersaturation was produced by mesoscale gravity waves. The superposition of two distinct wave packets lifted moist air upward within a relatively short time period and over a relatively small area around the meteorological station of Lindenberg. An operational radiosonde launched on 20 March 2000, 22:00 UTC detected the ISSR between 408 and $320 \mathrm{hPa}$ altitude.

The meteorological situation was dominated by an anticyclonic breaking Rossby wave which intruded subtropical air masses into mid-latitudes and polar regions (Fig. 1). The observation of the ISSR took place during an anti-cyclonic Rossby wave breaking event (P2, after Peters and Waugh, 1996). In the second phase of this event, the extruded air masses wrapped themselves anti-cyclonically forming a large, quasi-stationary ridge extending from the mid Atlantic toward the North Sea. During the time period considered in this study the ridge slowly expanded towards Central Europe. At the same time, a trough with its centre near the Black Sea propagated southeast and caused a nearly straight northeasterly jet streak between the pressure centres south

(C) 2005 Author(s). This work is licensed under a Creative Commons License. 


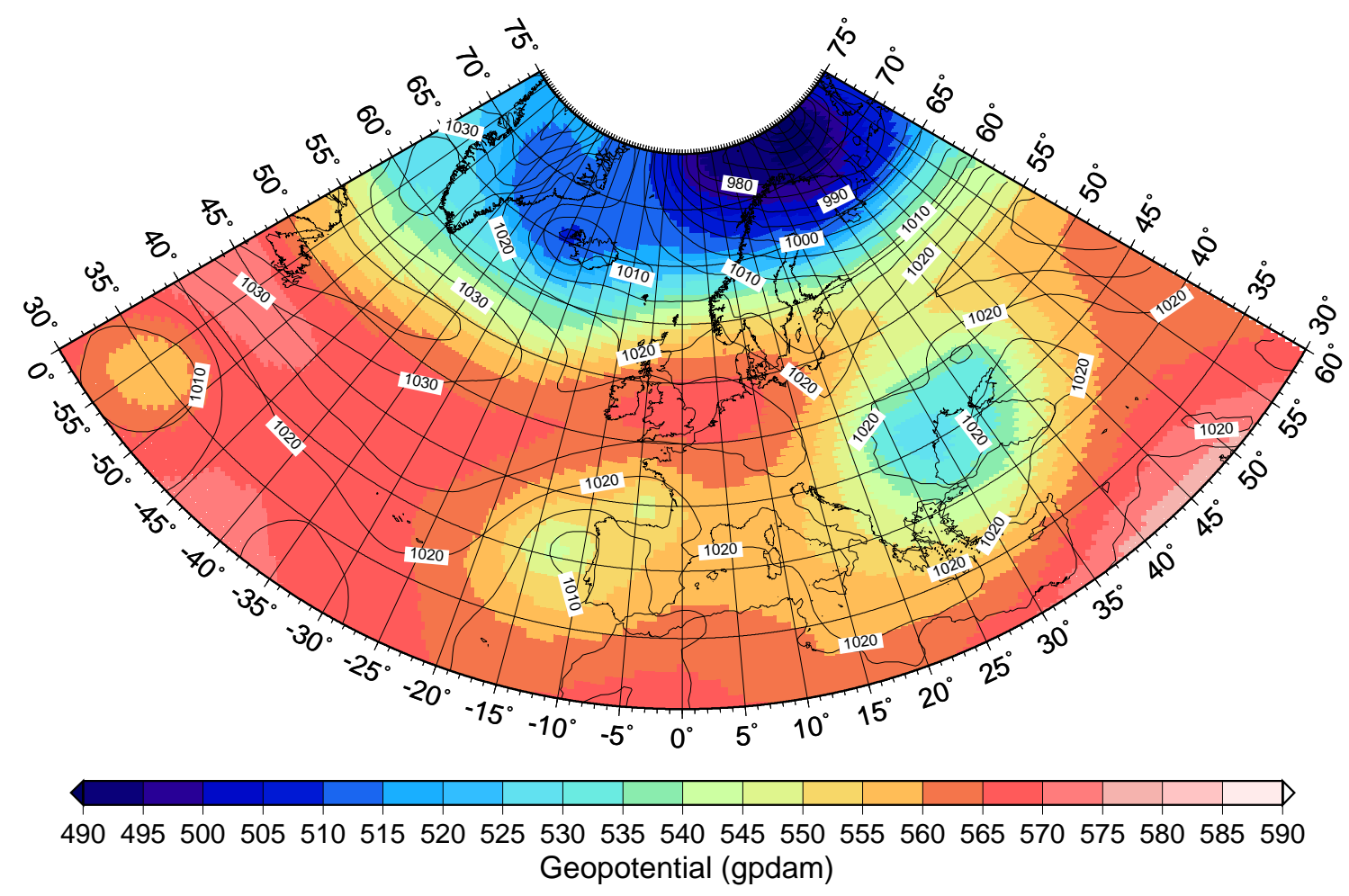

Fig. 1. Geopotential (colour, in gpdam) at $500 \mathrm{hPa}$ and surface pressure (black curves, isobars in hPa) for the $21 \mathrm{March} 2000,00: 00 \mathrm{UTC}$.

of the meteorological station of Lindenberg. North of Lindenberg, the mid-tropospheric flow was dominated by the strongly anti-cyclonically curved jet stream at the northeast flank of the ridge.

In the following section we describe the data sources and techniques applied for the analysis of this case; the analysis itself is presented in Sect. 3. In Sect. 4 we visualise the supersaturation field in the same way as we have done in Case 1, and conclusions are drawn in the final Sect. 5

\section{Data handling}

As in Case 1 we use a number of data sets that are briefly described in the following; for more details we refer to Case 1.

\subsection{Radiosoundings}

We use the vertical profiles (pressure, altitude, temperature and relative humidity with respect to ice) from the RS80A radiosoundings, corrected by the Lindenberg research team (see Spichtinger et al., 2003a). They have developed a technique to gauge and correct humidity measurements from routine RS80A radiosondes such that the results are very precise even in the cold and dry tropopause region (Nagel et al., 2001). Additionally, the horizontal wind (eastward and northward wind components $u$ and $v$ ) is available.

\subsection{METEOSAT infrared data}

We use METEOSAT infrared data and perform simple radiative transfer calculations (see below) with them, in order to distinguish between clear and cloudy air.

\subsection{Meteorological analyses and trajectory calculations}

Another database for our study are the operational analyses of the European Centre for Medium-Range Weather Forecasts (ECMWF) global assimilation scheme. We use the data with the same horizontal and vertical resolution as in Case 1 (T319L60, interpolated on a regular horizontal Gaussian grid, $0.6^{\circ} \times 0.6^{\circ} ; 60$ vertical levels between the surface and $0.1 \mathrm{hPa}$ ).

The operational analyses of ECMWF constitute the base for the LAGRangian ANalysis TOol (LAGRANTO, cf. Wernli and Davies, 1997), a three-dimensional trajectory model. This model is driven by the wind fields of ECMWF analyses and allows the calculation of kinematic Lagrangian trajectories.

As the $6 \mathrm{~h}$ time interval of the ECMWF data turns out to be too coarse for the analysis of the present case, we perform mesoscale numerical simulations of the situation using the weather prediction model MM5 (Dudhia, 1993; Dudhia et al., 2001) with a time step of $10 \mathrm{~s}$ and a minimum grid size of $9 \mathrm{~km}$ horizontally and about $150 \mathrm{~m}$ vertically. Mesoscale 
trajectories are calculated using the results of the numerical simulations.

\section{Case study of 21 March 2000, 00:00 UTC}

In this section we present the analysis of the data sets mentioned above.

\subsection{Radiosonde profiles and ECMWF analyses}

In Fig. 2 the vertical profiles of temperature, specific humidity, and relative humidity with respect to ice as obtained from the radiosounding are presented. Additionally, profiles obtained from ECMWF data, the thermal tropopause, and an ice supersaturation layer are shown. The specific humidity (radiosounding) is calculated from the variables temperature $(T)$, pressure $(p)$ and relative humidity with respect to ice $(\mathrm{RH} i)$. In the following we only describe the vertical profiles of temperature and relative humidity with respect to ice.

The temperature decreases with height from the surface to the thermal tropopause ( $p=183.2 \mathrm{hPa}$ ) with a few exceptions: At pressure levels 944, 831, 647 and $568 \mathrm{hPa}$ there are temperature inversions. The two lowest temperature inversions indicate the presence of low clouds (boundary layer clouds).

The relative humidity profile is much more complicated: From the surface to about $938 \mathrm{hPa}$ there is nearly water saturation. Above the first temperature inversion (at $944 \mathrm{hPa}$ ) RHi decreases to about $80 \%$, and above the second temperature inversion (at $831 \mathrm{hPa}$ ) even to about $30 \%$. Between 800 and $550 \mathrm{hPa}$ there are several local maxima and minima in the $R H i$-profile (mainly at the temperature inversions). $R H i$ increases strongly between $550 \geq p \geq 380 \mathrm{hPa}$ and the air is supersaturated in the pressure range $408 \geq p \geq 320 \mathrm{hPa}$ (with a shallow dip below saturation, namely to $97 \%$ ). Above the supersaturated layer $\mathrm{RHi}$ decreases first, but has another local maximum between 300 and $170 \mathrm{hPa}$ with values at about 90\%. Above the tropopause $R H i$ decreases rapidly. Humidity measurements in the upper troposphere are notoriously difficult and errors of the order of $10 \%$ generally must be accepted. However, the Lindenberg observatory has developed a technique to gauge and correct humidity measurements from routine RS80A radiosondes such that the results are claimed to be very precise even in the cold and dry tropopause region (Nagel et al., 2001). Fortunately the supersaturation between 408 and $320 \mathrm{hPa}$ reaches values in excess of $20 \%$ (i.e. $R H i>120 \%$ ). Hence we do not require that humidity measurements are much more accurate than the mentioned $10 \%$ for the present investigation.

In the following sections we will concentrate on the ice supersaturation layer $(p \approx 408-320 \mathrm{hPa}$ ) and the humid layer just below the tropopause ( $p \approx 275-170 \mathrm{hPa}$ ) in more detail. The ice supersaturation layer actually consists of two layers (in the radiosounding), because it has embedded in it a
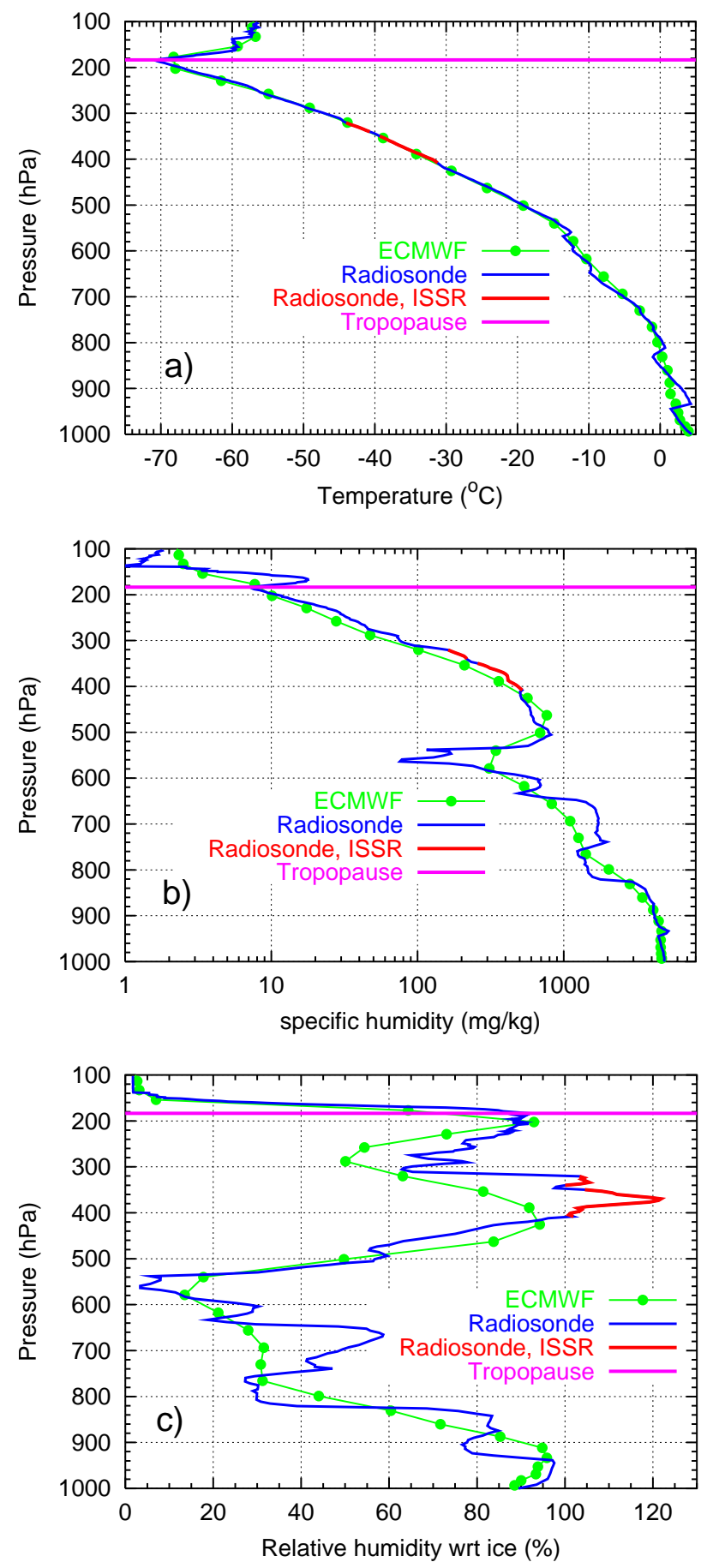

Fig. 2. Vertical profiles of the radiosonde (blue curve) and the corresponding values from the ECMWF data set (green filled circles and curve, values picked from the nearest grid points at every model level) for the 21 March 2000, 00:00 UTC. Additionally, the thermal tropopause (horizontal pink line) and the reported ice supersaturated layer (red curve) obtained from the radiosonde are shown. (a): temperature in degree Celsius; (b): specific humidity in milligrams water vapour per kilogram dry air; (c): relative humidity with respect to ice in percent. 
slightly subsaturated shallow layer of $150 \mathrm{~m}$ thickness. This gap between the supersaturation layers could be an artefact, since the radiosonde probably underestimates relative humidity when there is ice on the sensor housing.

We compare the radiosonde profile with the corresponding values from the ECMWF data, retrieved from the nearest grid point to the actual position of the radiosonde (calculated via the wind profile of the radiosonde). The temperature profile obtained from the radiosonde is well reproduced by the ECMWF analysis. However, the temperature inversions are missing as the vertical fine structure is not resolved by the model. The structure of the specific humidity profile (radiosonde) agrees qualitatively with the ECMWF model analyses, but there are quantitative differences: Especially in the pressure ranges $400-170 \mathrm{hPa}$ and $750-600 \mathrm{hPa}$ the ECMWF analyses mostly underestimate the specific humidity.

Also the structure of the $R H i$-profile is reproduced qualitatively quite well by the ECMWF model. But quantitatively the model profile shows some problems: Due to the underestimation of the specific humidity the relative humidity is also underestimated in the pressure range $400-170 \mathrm{hPa}$. The maximum in the relative humidity profile is shifted to higher pressures values (i.e. downwards) and, in particular, the relative humidities do not exceed saturation. Nevertheless, the qualitative agreement between the modelled and the measured $\mathrm{RHi}$ profiles encourage us to proceed with the analysis based on the ECMWF data. Although the Lindenberg radiosonde data are assimilated into ECMWF analyses, the agreement is not self-evident, since only the uncorrected humidity data are used in the assimilation procedure while we use corrected data to detect ice supersaturation.

\subsection{Trajectory calculations}

\subsubsection{Trajectories}

The time of the ISSR detection by the radiosonde over Lindenberg on 21 March 2000 00:00 UTC will be referred to as $t=0 \mathrm{~h}$ and other times will be expressed relative to this date.

We calculate forward $(t=0 \mathrm{~h} \rightarrow t=+24 \mathrm{~h})$ and backward $(t=0 \mathrm{~h} \rightarrow t=-36 \mathrm{~h})$ trajectories of air parcels released in a starting region around Lindenberg $\left(14.12^{\circ} \mathrm{E} / 52.22^{\circ} \mathrm{N}\right)$ : longitude $13.2-16.2^{\circ} \mathrm{E}$, latitude $51.0-53.4^{\circ} \mathrm{N}$, pressure 170 $510 \mathrm{hPa}$ (i.e. ECMWF model levels 29-40). For $t=0 \mathrm{~h}$ we determine for each ECMWF model level the nearest grid point to the actual radiosonde position called the main grid point. The trajectory through each of the 12 level-dependent main grid points is called the main trajectory in the following discussion. Additionally, the trajectories through the four adjacent grid points are considered. The trajectories are labelled in the following way: $\operatorname{Tr}_{\ell, i}$, where $\ell$ denotes the ECMWF model level which the trajectory touches at $t=0 \mathrm{~h}$. The index $i$ is 1 for the main trajectory and $2-5$ for the other trajectories (counted counterclockwise, starting at the northern grid point).
The trajectory pattern was characterised by the anticyclonic flow around the ridge over the North Sea. During the time interval $[-36,-6] \mathrm{h}$ the mid-tropospheric westerly wind carried the air parcels over the southern tip of the Scandinavian Alps. A coherent vertical displacement with a peak-to-peak amplitude of $\sim 70 \mathrm{hPa}$ occurred in all trajectories due to mountain wave activity. In the following time interval $[-6,+24] \mathrm{h}$ the air parcel trajectories wrapped anticyclonically around the ridge without significant changes in altitude. Other backward trajectories released further east of Lindenberg (not shown) display a diffluent region at the northeastern edge of the anticyclone in accordance with the flow pattern shown in Fig. 1.

\subsubsection{Contributions to the change of relative humidity}

Ice supersaturation is analysed on the ECMWF model levels $34-36$ (with $p_{34} \approx 320 \mathrm{hPa}, p_{35} \approx 345 \mathrm{hPa}, p_{36} \approx 390 \mathrm{hPa}$ ). Hence, we calculate the contributions of the variables $T, q$ and $p$ to the change of the relative humidity along the trajectories $\operatorname{Tr}_{34, \mathrm{i}}-\operatorname{Tr}_{36, \mathrm{i}}$. As in Case 1 we assume that a linearisation is possible, i.e. we compute the total differential

$d R H i=\frac{\partial R H i}{\partial T} d T+\frac{\partial R H i}{\partial q} d q+\frac{\partial R H i}{\partial p} d p$.

The result of the calculations suggests that ice supersaturation along the trajectories $\operatorname{Tr}_{34, \mathrm{i}}-\operatorname{Tr}_{36, \mathrm{i}}$ was caused during the time-step $t=-6 \mathrm{~h} \rightarrow t=0 \mathrm{~h}$ through a large increase of the specific humidity $q$ by a factor of about 1.5 to 1.75 . The temperature decreases only marginally during this period.

As explained in the Appendix, a large $q$-change along a Lagrangian trajectory can either be due to cloud processes occuring in the observed air parcel, or it can point to the failure of the trajectory calculation due to unresolved motions. In the present case we have no indication from METEOSAT or other satellite imagery that evaporating clouds could have been the origin of the large increase of $q$. Hence, we must conclude that the trajectories based on 6-h analyses are too coarse to reveal important details of the dynamics (see also Stohl and Seibert, 1998). Indeed, a closer look to the radiosonde and ECMWF profiles of specific humidity at $-6 \mathrm{~h}$ and $0 \mathrm{~h}$ suggests a vertical uplift of about $30 \mathrm{hPa}$ in the pressure range $450 \geq p \geq 220 \mathrm{hPa}$. This strong ascent is not resolved by the trajectories based on 6-hourly wind data. The origin of this fast and supposedly small-scale uplift is not clear from the available data. After testing different hypotheses, we conjecture that the localised ascent was caused by internal gravity waves. In order to check this hypothesis we perform a mesoscale simulation which will be discussed in Sect. 3.4. But before this discussion we want to check for cloud presence in the supersaturation layer; this is investigated in the next section. 

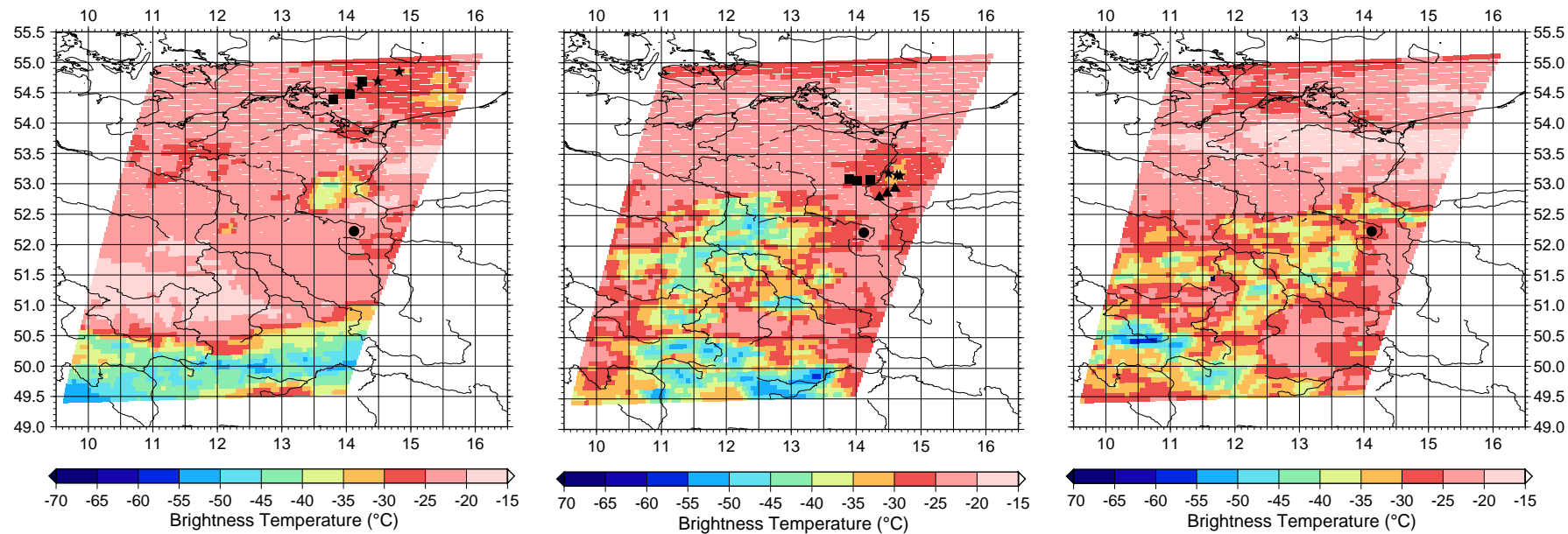

Fig. 3. Infra red METEOSAT image of the region "GermanyNE" at 17:30 UTC (left), 21:30 UTC (middle) and 23:00 UTC (right) on 20 March 2000. Additionally, the positions of Lindenberg (filled circle, $14.12^{\circ} \mathrm{E} / 52.22^{\circ} \mathrm{N}$ ), of the main trajectories $\operatorname{Tr}_{34,1}-\operatorname{Tr}_{36,1}($ black squares), of the neighbouring trajectories $\operatorname{Tr}_{34,5}-\operatorname{Tr}_{36,5}$ (black stars) and of the air parcels measured by the radiosonde (black triangles, only for 21:30 UTC) are shown. At 23:00 UTC the air parcels are so close to Lindenberg, that we only plotted the position of Lindenberg.
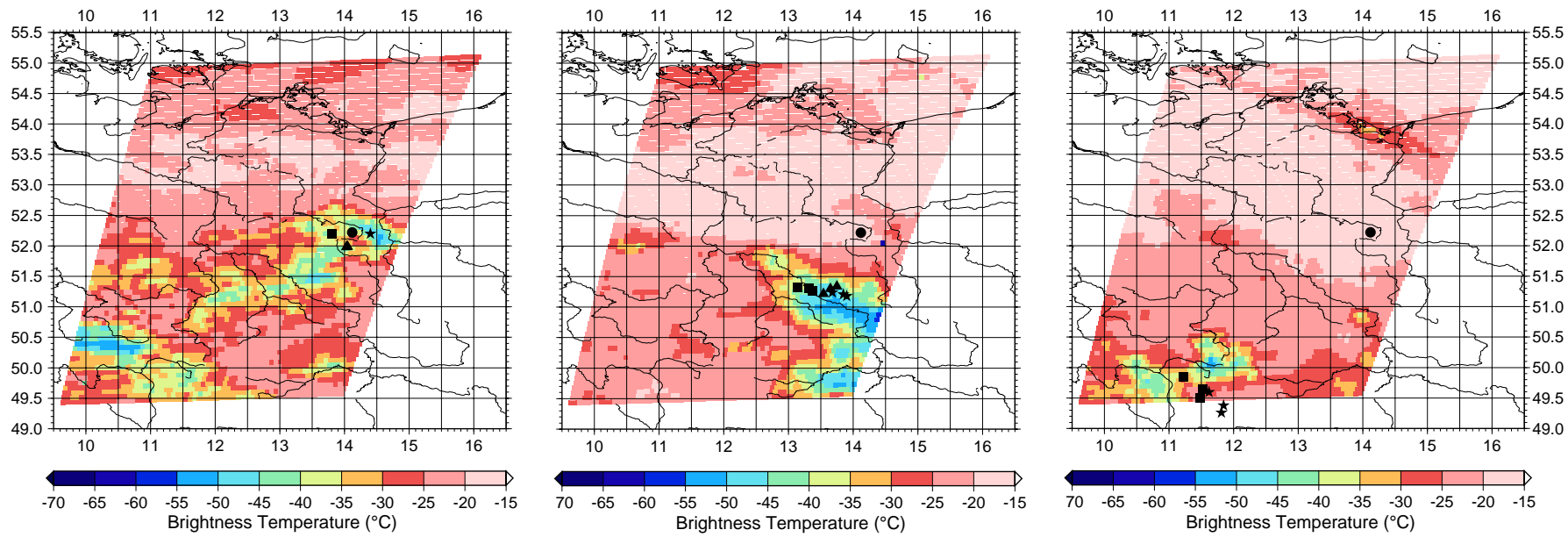

Fig. 4. As Fig. 3, but at 23:30 UTC on 20 March 2000 (left), 01:30 UTC (middle) and 05:30 UTC (right) on 21 March 2000. Additionally, the positions of the air parcels measured by the radiosonde (black triangles, only 23:30 UTC and 01:30 UTC) are shown.

\subsection{Check for cloud presence}

In this section we examine the cloud evolution using METEOSAT infrared imagery. Figures 3 and 4 cover the period from 20 March 2000, 17:30 UTC to 21 March 2000, 05:30 UTC. Lindenberg is indicated as a black bullet on these figures. The positions of the air parcels that were crossed by the radiosonde on ECMWF model levels 34-36 (i.e. $p_{34} \approx 320 \mathrm{hPa}, p_{35} \approx 345 \mathrm{hPa}, p_{36} \approx 390 \mathrm{hPa}$ ) at the nominal time 00:00 UTC are marked on some of the figures as black triangles. These positions are computed from the measured wind data for a time frame of $\pm 3 \mathrm{~h}$ around the ra- diosonde ascent. Additionally, the positions of the main trajectories $\operatorname{Tr}_{34,1}, \operatorname{Tr}_{35,1}, \operatorname{Tr}_{36,1}$ (start at $13.8^{\circ} \mathrm{E} / 52.2^{\circ} \mathrm{N}$, black squares) and the trajectories $\operatorname{Tr}_{34,5}, \operatorname{Tr}_{35,5}, \operatorname{Tr}_{36,5}$ (start at $14.4^{\circ} \mathrm{E} / 52.2^{\circ} \mathrm{N}$, black stars) are marked. At 23:00 UTC all these air parcels are so close to Lindenberg that we have only plotted the bullet for this location.

Between 17:30 UTC and 23:00 UTC all calculated positions are situated in regions where the mean brightness temperature (within a square of edge length $=30 \mathrm{~km}$ centred at the respective position) ranged between -30 and $-20^{\circ} \mathrm{C}$ with standard deviations of $1-2 \mathrm{~K}$. As the physical temperatures of the considered air parcels were much colder ( -35 to 


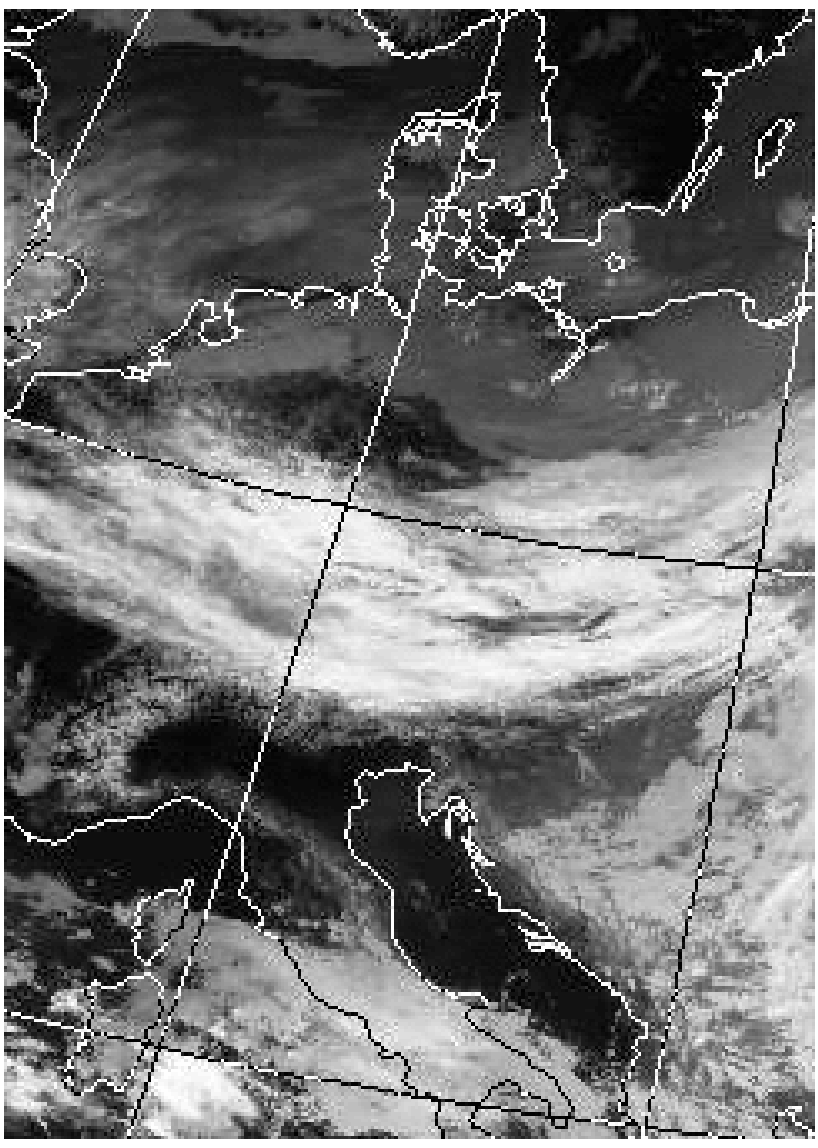

Fig. 5. AVHRR - IR: 20 March 2000, 16:01 UTC, kindly provided by NERC Satellite Receiving Station, Dundee University, Scotland (http://www.sat.dundee.ac.uk/).

$-45^{\circ} \mathrm{C}$ ) than the brightness temperatures we can assume that they were cloud free during that time, based on our radiative calculations (not shown).

At 23:30 UTC (the date of the radiosonde ascent) the situation changed: The mean brightness temperatures at the positions of the considered air parcels decreased to significantly lower values $\left(-40 \leq \bar{T} \leq-35^{\circ} \mathrm{C}\right)$ and their standard deviations increased to values of 5-7 K. The METEOSAT imagery at later times (Fig. 4) shows even lower brightness temperatures at the air parcels' positions. This evolution suggests that during the radiosonde ascent a (cirrus) cloud began to form in the ice supersaturated region that became opaque within about $2 \mathrm{~h}$.

Before we estimate the properties of the cloud that formed while the radiosonde ascended we take a look at the whole scene. The reason is that the brightness temperature nowhere reached higher values than $-15^{\circ} \mathrm{C}$, even at places where no clouds are evident on the corresponding infrared image obtained by AVHRR (Fig. 5). However, the AVHRR image seems to display a feathery veil over locations where one can see the ground. This suggests that a horizontally extended cirrus cloud is present below the tropopause. The optical thickness of this cirrus can be estimated using the simple radiative transfer equations from Case 1 . Using the radiosonde profiles $(T, q, R H i)$ from 20 March 2000, 18:00 UTC, and ECMWF profiles at the positions of the main trajectories at that time we find a very humid layer between 210 and $170 \mathrm{hPa}$, above a rather dry lower and middle troposphere. Whereas the METEOSAT brightness temperature ranged between -26 and $-21^{\circ} \mathrm{C}$, the temperature of the "cirrus" layer was about $-68^{\circ} \mathrm{C}$ and the surface temperature can be estimated as $T_{\text {surf }} \approx 1.3^{\circ} \mathrm{C}$. These values result in an estimate of optical depth in the range $0.31 \leq \tau \leq 0.43$ at the wavelength $\lambda=11.5 \mu \mathrm{m}$.

Now we return to the cirrus that formed in the icesupersaturated region just at the time of the radiosonde's ascent over Lindenberg. The optical thickness of this cloud (at about $p \approx 340 \mathrm{hPa}$ ) can be calculated from a slight generalisation of the equations derived in Case 1 , where we have to take into account not only the cloud itself (subscript 2 in the formula below) and the underlying surface or boundary layer clouds, but additionally the cold cirrus at the tropopause (subscript 1). In this situation and with the simplifying assumptions of Case 1, the radiance measured by a satellite is:

$$
\begin{aligned}
I_{\text {sat }} & =B_{\lambda}\left(T_{1}\right)\left(1-e^{-\frac{\tau_{1}}{\mu}}\right) \\
& +\left(B_{\lambda}\left(T_{\text {surf }}\right) e^{-\frac{\tau_{2}}{\mu}}+B_{\lambda}\left(T_{2}\right)\left(1-e^{-\frac{\tau_{2}}{\mu}}\right)\right) e^{-\frac{\tau_{1}}{\mu}},
\end{aligned}
$$

with the Planck function $B_{\lambda}$ for wavelength $\lambda$ at the temperatures of the clouds $T_{1,2}$ and the underlying surface $T_{\text {surf }}$. The factor $1 / \mu$ corrects the vertically measured optical thickness for the slanted viewing geometry: $\mu$ is the cosine of the zenith distance of the satellite seen from Lindenberg, which is equivalent to the geographical latitude of that location. The brightness temperature is defined as $I_{\mathrm{sat}}=B_{\lambda}\left(T_{\mathrm{br}}\right)$. By rearranging Eq. (2) the optical depth $\tau_{2}$ of the lower cloud is:

$$
\begin{aligned}
\tau_{2} & =\mu \cdot\left[\log \left(\left(B_{\lambda}\left(T_{\text {surf }}\right)-B_{\lambda}\left(T_{2}\right)\right) e^{-\frac{\tau_{1}}{\mu}}\right)\right. \\
& \left.-\log \left(B_{\lambda}\left(T_{\mathrm{br}}\right)-B_{\lambda}\left(T_{2}\right) e^{-\frac{\tau_{1}}{\mu}}-B_{\lambda}\left(T_{1}\right)\left(1-e^{-\frac{\tau_{1}}{\mu}}\right)\right)\right](3)
\end{aligned}
$$

For the calculation of the optical depth we use the following: At 00:00 UTC the surface temperature equals the temperature of the top of the opaque boundary layer cloud, i.e. $T_{\text {surf }} \approx 3.0^{\circ} \mathrm{C}$. The optical depth of the high cloud is $\tau_{1}=0.37$, the cloud temperature is $T_{1}=-68^{\circ} \mathrm{C}$. The cloud temperature of the lower cloud can be estimated using the temperature profile (radiosonde) as $T_{2}=-42.33^{\circ} \mathrm{C}$, i.e. the mean temperature within the top $400 \mathrm{~m}$ of the cloud. There is no qualitative difference if we use for $T_{2}$ the cloud top temperature $T=-44^{\circ} \mathrm{C}$ for our calculations. Since the brightness temperatures were changing considerably from 00:00 UTC, we compute a range of optical thicknesses for the range of brightness temperatures from -30 to $-49^{\circ} \mathrm{C}$ as they occurred in the METEOSAT data. The results are presented in Table 1. 
Additionally, we calculate the ice water content (IWC) for the two cirrus clouds (cf. Case 1):

$\mathrm{IWC}=\frac{\tau}{\beta \cdot \Delta z \cdot\left(\alpha_{i}+\frac{\gamma_{i}}{r_{\mathrm{eff}}}\right)}$.

First, we estimate the ice water content for the higher cirrus. From the radiosonde profile we find a thickness of the cloud layer of about $2 \mathrm{~km}$. From Ebert and Curry (1992) we take the constants $\alpha_{i}=0.0016 \mathrm{~m}^{2} \mathrm{~g}^{-1}, \quad \gamma_{i}=1.166 \mathrm{~m}^{2} \mathrm{~g}^{-1} \mu \mathrm{m}^{-1}$ and $\beta=1.66$. Because of the very low temperatures inside the cirrus layer $\left(-71 \leq T \leq-58^{\circ} \mathrm{C}\right)$ we can assume a small effective radius of the ice crystals, for our calculation we set $r_{\text {eff }}=10 \mu \mathrm{m}$. Then, for an optical depth in the range $0.31 \leq \tau_{1} \leq 0.43$ we obtain an IWC between 0.80 and $1.11 \mathrm{mg} \mathrm{m}^{-3}$. The total water content inside this layer can be estimated as about $5.3-6.2 \mathrm{mg} \mathrm{m}^{-3}$. The empirical formula of Schumann (2002),

$\operatorname{IWC}(T)=\exp \left(6.97+0.103 \cdot T\left({ }^{\circ} \mathrm{C}\right)\right) \frac{\mathrm{mg}}{\mathrm{m}^{3}}$,

gives for a mean temperature inside the cloud layer of about $-65^{\circ} \mathrm{C}$ a mean IWC of $1.3 \mathrm{mg} \mathrm{m}^{-3}$ which is not far outside the range of the values obtained from the calculation by using the optical depth $\tau_{1}\left(0.80 \leq \mathrm{IWC} \leq 1.11 \mathrm{mg} \mathrm{m}^{-3}\right)$.

Inside the lower, just forming cirrus cloud, we find a much larger variability of the brightness temperatures that is due to the fast evolution of this cloud. This also implies a larger uncertainty in our estimates for optical depth and ice water content of this cloud. For 23:30 UTC when the cloud is just forming, we assume $r_{\mathrm{eff}}$ is between 10 and $20 \mu \mathrm{m}$. But later, at 01:30 UTC, when the cloud approaches equilibrium (i.e. saturation), we assume larger ice crystals with $r_{\text {eff }}$ between 30 and $50 \mu \mathrm{m}$. We also have to take into account the variation of the optical thickness (see Table 1): For 23:30 UTC we consider the lower values of $\tau_{2}(0.235$ to 0.763$)$ as relevant, and for 01:30 UTC the higher values (0.640 to 1.444), because the cloud became opaque. The thickness of the ice supersaturated layer was $\Delta z \approx 1600 \mathrm{~m}$. With this input we estimate $0.74 \leq \mathrm{IWC} \leq 4.7 \mathrm{mg} \mathrm{m}^{-3}$ for $23: 30 \mathrm{UTC}$ and $4.0 \leq \mathrm{IWC} \leq 21.8 \mathrm{mg} \mathrm{m}^{-3}$ for 01:30 UTC. The temperature inside the cloud layer ranged from -44 to $-31.2^{\circ} \mathrm{C}$, the mean value is $\bar{T}=-37.4^{\circ} \mathrm{C}$. Hence, the formula of Schumann (2002) gives $11.5 \leq \mathrm{IWC}(T) \leq 42.8 \mathrm{mg} \mathrm{m}^{-3}$ and $\operatorname{IWC}(\bar{T})=22.6 \mathrm{mg} \mathrm{m}^{-3}$. These values are in good agreement to the values calculated from the optical thicknesses for 01:30 UTC (see above). At this time the cirrus cloud was probably close to equilibrium which is a condition for the validity of the formula of Schumann (2002).

The total water concentration in the supersaturated layer can be estimated from the specific humidity profile determined from the radiosonde data: $\bar{q}_{\text {tot }}=180 \mathrm{mg} \mathrm{m}^{-3}$. Hence, the ice phase consisted of about 0.4 to $2.2 \%$ of the total water at 23:30 UTC when the cirrus was just forming. Later when the cloud approached equilibrium, about 2 to $12 \%$ of the total water was in the ice phase. This is much less than we would
Table 1. Values of the optical depth $\tau_{2}$ for different brightness temperatures, calculated using Eq. (3).

\begin{tabular}{ccccc}
\hline$T_{\mathrm{br}}\left({ }^{\circ} \mathrm{C}\right)$ & -30 & -36.5 & -40 & -42 \\
\hline$\tau_{2}$ & 0.235 & 0.473 & 0.640 & 0.755 \\
\hline$T_{\mathrm{br}}\left({ }^{\circ} \mathrm{C}\right)$ & -45 & -46 & -49 & \\
\hline$\tau_{2}$ & 0.973 & 1.063 & 1.444 & \\
\hline
\end{tabular}

estimate for a cirrus forming by homogeneous nucleation, because this would have required at least $40 \%$ supersaturation which translates to about the same proportion in the ice phase when equilibrium is established.

\subsection{Mesoscale simulation}

\subsubsection{Model setup}

The mesoscale fields are calculated with the non-hydrostatic weather prediction model MM5-version 3.4 (Dudhia, 1993; Dudhia et al., 2001). The outer model domain is centred at $\left(52^{\circ} \mathrm{N}, 10^{\circ} \mathrm{E}\right)$ with an extension of $4401 \mathrm{~km} \times 4401 \mathrm{~km}$. In this domain a horizontal grid size of $\Delta x=27 \mathrm{~km}$ is used. A local grid refinement scheme with a nested domain of $9 \mathrm{~km}$ horizontal resolution is applied to resolve most of the horizontal wavenumber spectrum of gravity waves excited either by the orography or by jet stream instabilities. The model has 200 vertical levels up to the model top at $10 \mathrm{hPa}$ (with $\Delta z \approx 150 \mathrm{~m}$ ). Turbulent and moist processes are accounted for by standard schemes: Hong and Pan (1996) turbulence scheme, Grell's cumulus parameterisation (Grell et al., 1994) and Reisner's microphysical scheme (Reisner et al., 1998). The initial condition at 20 March 2000 12:00 UTC and the boundary values of the model integration are prescribed by operational analyses from the ECMWF model with a horizontal resolution of $0.5^{\circ}$ in latitude and longitude and 15 pressure levels between 1000 and $10 \mathrm{hPa}$. The mesoscale model MM5 has been extensively used to study the dynamics of inertia gravity waves (Zhang, 2004; Dörnbrack, 1999, 2002).

\subsubsection{Results}

Results of the mesoscale model simulation confirm the hypothesis of ascending air between 7 and $10 \mathrm{~km}$ altitude near Lindenberg induced by internal gravity waves. Figure 6 details the meteorological situation at the $318 \mathrm{~K}$ isentropic surface $(\approx 9 \mathrm{~km}$ altitude) at 21 March 2000, 01:00 UTC (cf. Fig. 1). As at $500 \mathrm{hPa}$, the large-scale upper-tropospheric flow is dominated by the ridge over northern Germany and the anti-cyclonically curved jet stream. However, mesoscale perturbations seen as vertical wind fluctuations appear in two areas north and south of Lindenberg (Fig. 7). 


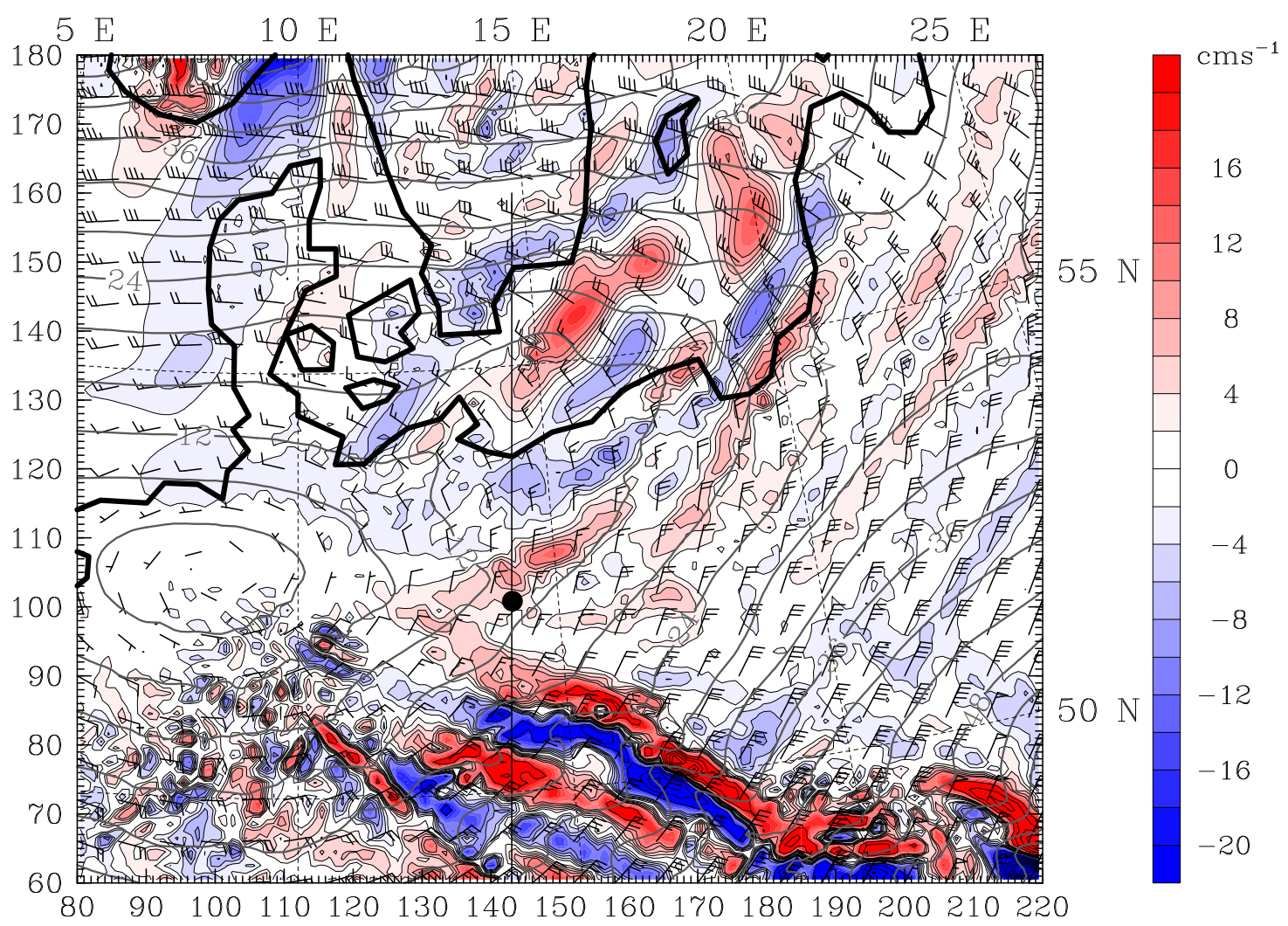

Fig. 6. Vertical velocity $\left(\mathrm{cms}^{-1}\right.$, colour shaded and thin black iso-contours with $\Delta w=2 \mathrm{cms}^{-1}$ and horizontal wind speed (m/s, barbs; long: $10 \mathrm{~ms}^{-1}$, short $5 \mathrm{~ms}^{-1}$, and gray iso-contours with $\Delta u=4 \mathrm{~ms}^{-1}$ interval) at the isentropic surface $318 \mathrm{~K}$ valid at $21 \mathrm{March} 200001: 00 \mathrm{UTC}$ ( $+13 \mathrm{~h}$ simulation time). The labels denote longitude/latitude (top and right boundary) or number of MM5 grid points (bottom and left boundary), respectively. Numerical results from the innermost domain with $\Delta x=9 \mathrm{~km}$ (distance between small tick marks) are shown. The black dot marks the location of Lindenberg and the straight north-south line is the base line of the vertical section in Fig. 7 (the actual start of the line is 20 grid cells to the south).

Coherent wave packets with a horizontal wavelength $\lambda_{h} \approx 200-225 \mathrm{~km}$ are simulated at the north-eastern edge of the ridge. They extend from Lindenberg over the Baltic Sea toward southern Sweden (Fig. 6). In this region, the maximum curvature of the jet causes a strongly unbalanced flow regime which is subject to inertial instability. Inertia gravity waves are excited on the anti-cyclonic side of the jet stream. This simulation result is in agreement with former studies showing that strongly diffluent regions are preferred locations for the excitation of inertia gravity waves (Knox, 1997; Plougonven et al., 2003; Peters et al., 2003). Due to the wrapping up of the anti-cyclonically breaking Rossby wave, the simulated inertia gravity wave packets get strongly dispersed in the curved flow.

The hodograph analysis of the radiosonde profile of the 21 March 2000 00:00 UTC sounding shows a cyclonic rotation of the wind vector with height between 8 and $11 \mathrm{~km}$ altitude (Fig. 8). This indicates a downward propagating gravity wave (Gill, 1982). Hence, the gravity wave source is located in the upper troposphere; this is consistent with the simulated mesoscale flow. The wave parameters can be determined by fitting the hodograph with the linear polarisation relationship of inertia gravity waves

$\begin{aligned} u^{\prime} & =\hat{u} R(\Theta) \cos (m z+\Phi) \\ v^{\prime} & =-\hat{u} R(\Theta) \frac{f}{\omega_{0}} \sin (m z+\Phi),\end{aligned}$

where $\hat{u}$ is the amplitude of the wave, $m$ and $\omega_{0}$ are its vertical wavenumber and intrinsic frequency, and $f$ is the Coriolis parameter (Thompson, 1978). The matrix $R(\Theta)$ rotates the reference frame in such a way that the phase speed of the wave is parallel to the $\mathrm{x}$-axis. The polarisation relationship states that the ratio between the major and minor ellipse axes is equal to $\omega_{0} / f$. From Fig. 8, we find $\omega_{0}=2.8 f$, a typical value for an inertia gravity wave (Peters et al., 2003; Plougonven et al., 2003). The result of the fit with $\hat{u}=0.5 \mathrm{~m} \mathrm{~s}^{-1}$ gives a vertical wavenumber $m=3.810^{-3} \mathrm{~m}^{-1}$, i.e. the vertical wavelength is $\lambda_{v} \approx 1.6 \mathrm{~km}$. The horizontal wave number is determined from the dispersion relationship

$m^{2}=\frac{N^{2}-\omega_{0}^{2}}{\omega_{0}^{2}-f^{2}}\left(k^{2}+l^{2}\right)$ 


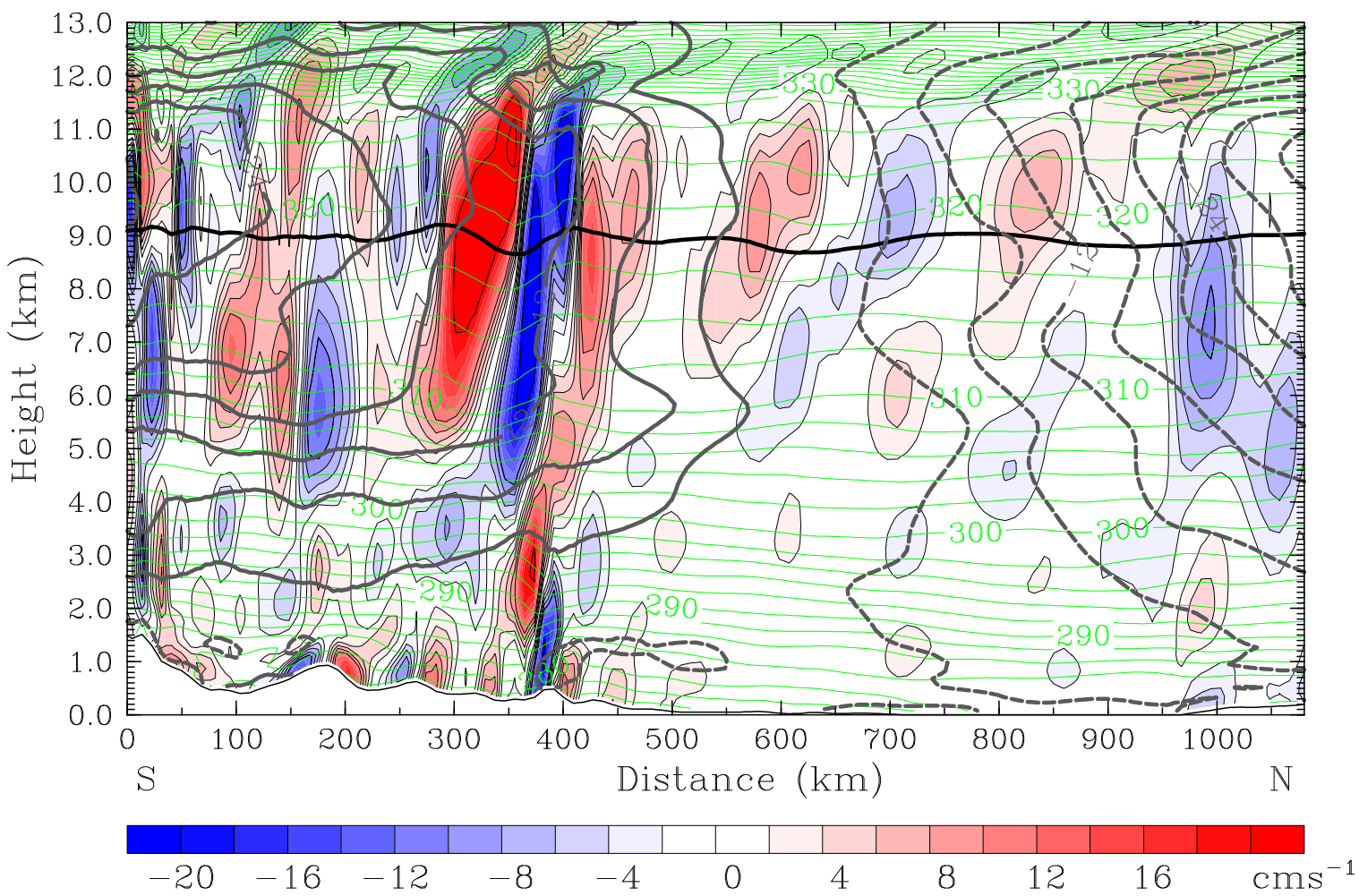

Fig. 7. Vertical velocity ( $\mathrm{cms}^{-1}$, scaling as in Fig. 6), potential temperature (K, green iso-contours, $2 \mathrm{~K}$ increment), and plane normal horizontal wind speed ( $\mathrm{ms}^{-1}$, gray iso-contours with $\Delta u=4 \mathrm{~ms}^{-1}$, dashed out of, solid into the plane) along the base line indicated in Fig. 6 valid at 21 March 2000 01:00 UTC ( $+13 \mathrm{~h}$ simulation time). The location of Lindenberg is just in the middle of section at about $575 \mathrm{~km}$ horizontal distance. The black line at $318 \mathrm{~K}(\sim 9 \mathrm{~km}$ height $)$ marks the height of the section in Fig. 6 . Numerical results from the innermost domain with $\Delta x=9 \mathrm{~km}$.

with $N$ as the buoyancy frequency; we have used $\tan \Theta=|l / k|$. In our case $\Theta=45^{\circ}$, so $l=k$. The estimates of the horizontal wavelength $\lambda_{h}$ range from $120 \mathrm{~km}$ for $N=0.015 \mathrm{~s}^{-1}$ to $200 \mathrm{~km}$ for $N=0.025 \mathrm{~s}^{-1}$. Although the hodograph method has uncertainties (Zhang et al., 2004), the values of $\lambda_{h}$ agree quantitatively with those from the mesoscale numerical simulation, which are $\lambda_{h} \approx 200-225 \mathrm{~km}$. However, estimating the vertical wavelength from the numerical results is difficult as the region around Lindenberg is superimposed by internal waves from different sources. In Fig. 7, two wave trains are present north of Lindenberg: a quasi-horizontal wave pattern with a relatively short vertical wave length $\lambda_{v} \sim 2 \mathrm{~km}$ and a downward extending wave train with $\lambda_{v} \sim 5 \mathrm{~km}$. Whereas the first wave train represents the inertia gravity wave excited in the diffluent region of the jet stream, the second one might be generated by upward propagating mountain waves. It should be noted that the tropopause is extremely sharp in the anticyclone, hence, reflected wave modes might be present in the numerical simulation results, too. The values of $\lambda_{v}$ obtained by the hodograph method $\left(\lambda_{v} \approx 1.6 \mathrm{~km}\right)$ are in a good agreement with those from the mesoscale numerical simulation of the first wave train.
The other area of mesoscale flow perturbations is located south of Lindenberg. There, surface winds of $\approx 10 \mathrm{~m} \mathrm{~s}^{-1}$ past the Erzgebirge and Riesengebirge excite vertically propagating mountain waves with $\lambda_{h}<100 \mathrm{~km}$ that produce a quasistationary wave pattern at the south-east edge of the high pressure ridge. Although the maximum vertical velocities directly above the mountains exceed $0.5 \mathrm{~m} \mathrm{~s}^{-1}$ the magnitude of the vertical wind in a distance of $150 \mathrm{~km}$ south of Lindenberg is similar to the amplitude in the inertia gravity waves.

The vertical section in Fig. 7 reveals the different spatial structures of the simulated inertia gravity waves north and the mountain waves south of Lindenberg. In Fig. 7 the inertia gravity wave pattern appears as a nearly horizontal band of updraughts and downdraughts with maximum vertical velocities of about $10 \mathrm{~cm} \mathrm{~s}^{-1}$ above and north of Lindenberg whereas the mountain waves propagate from below.

Figure 9 shows a series of pseudo-soundings (i.e. vertical profiles at a grid point) of specific humidity at Lindenberg, using the MM5 output for times between -6 and $+6 \mathrm{~h}$ around the reference time. The later soundings appear as upward shifted versions of earlier soundings, which means that on a fixed pressure level the specific humidity increases with time as a result of moist advection from below. Trajectories 


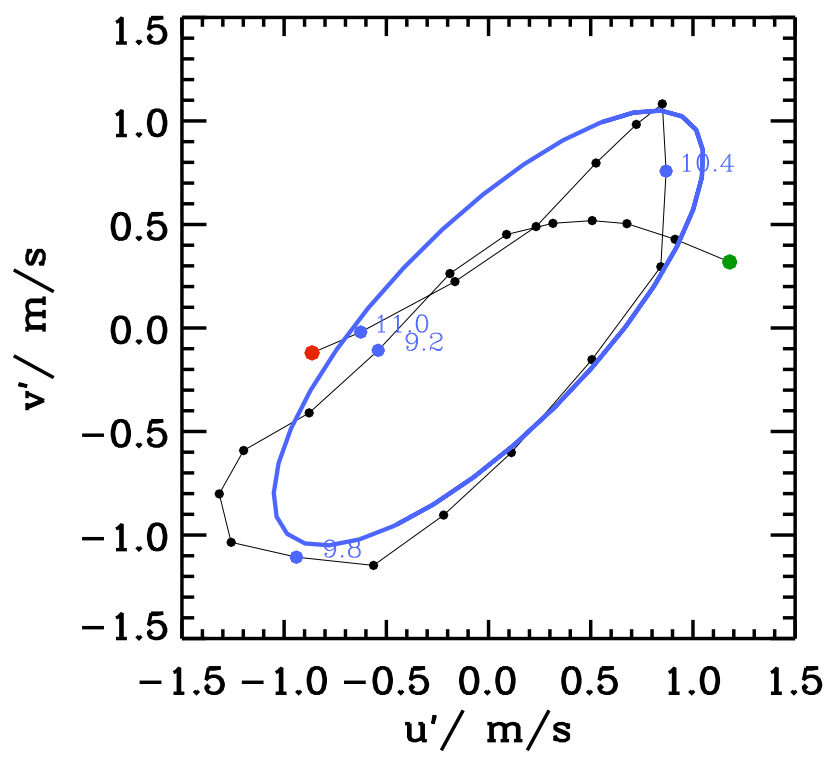

Fig. 8. Hodograph (black) of the zonal $u^{\prime}$ and meridional $v^{\prime}$ wind fluctuations between $\sim 8 \mathrm{~km}$ (green dot) and $\sim 11 \mathrm{~km}$ (red dot) generated by the inertia gravity wave derived from the 21 March 2000 00:00 UTC radiosonde sounding. The blue curve shows the fit of wind fluctuations calculated according to the linear polarisation relationship of inertia gravity waves (see text). The numbers $(9.2,9.8$, $10.4,11.0)$ indicate height in $\mathrm{km}$.

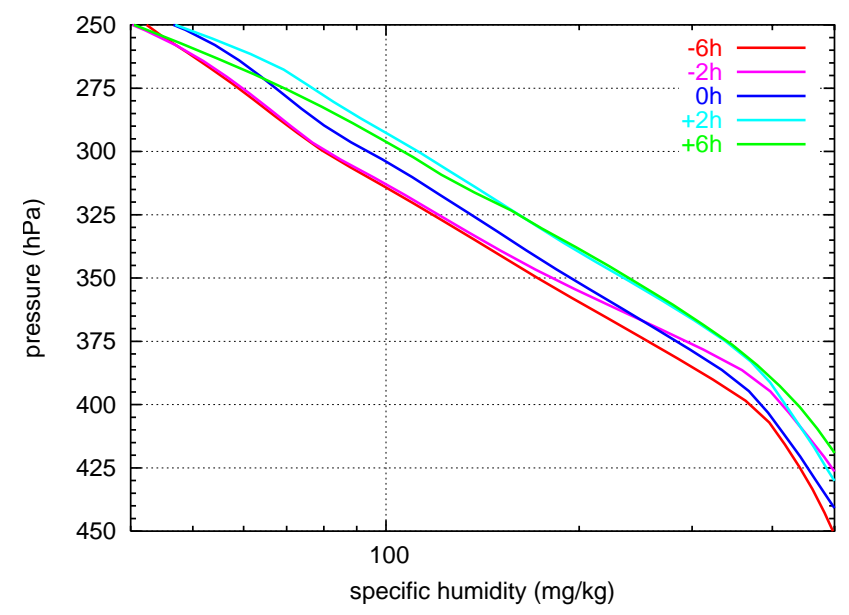

Fig. 9. Pseudo-soundings of specific humidity for various times relative to the reference time, taken from MM5 output at the grid point closest to Lindenberg. Later profiles appear as upward shifted versions of earlier ones.

based on the MM5 wind fields show an overall upward motion (with intermittent downward excursions) in the upper troposphere over and around Lindenberg before the observation of the ISSR (Fig. 10), whereas ECMWF trajectories show no uplift.

Both wave systems, the mountain wave and the jet-stream induced inertia gravity wave, become superimposed in an

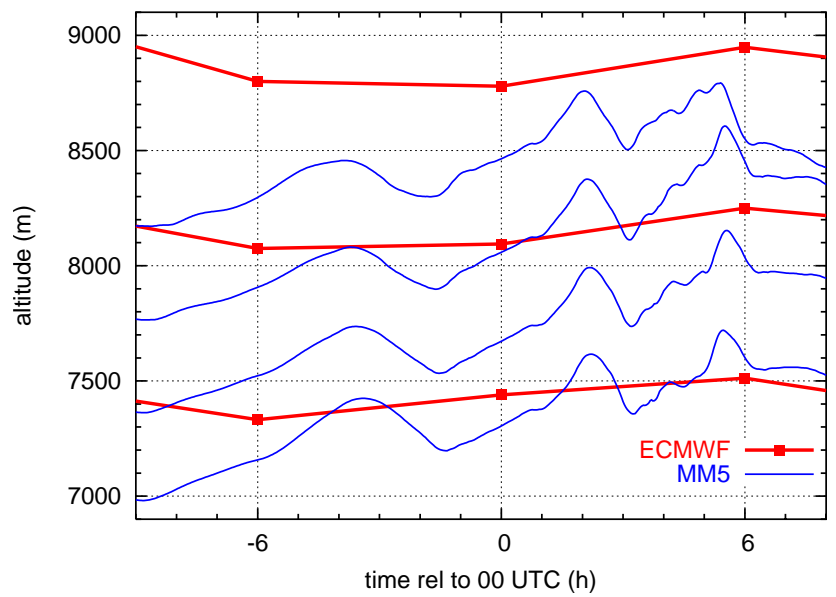

Fig. 10. Altitude variation of MM5 trajectories (blue lines) that cross the grid point of Lindenberg at the reference time, computed using the MM5 wind field. Overall, the MM5 trajectories ascend, in particular about $t=0 \mathrm{~h}$, with the exception of some intermittent downward excursions. Additionally, ECMWF trajectories $\left(\operatorname{Tr}_{34,1}-\operatorname{Tr}_{36,1}\right.$, red lines and filled squares) are shown. There are only small vertical velocities $(|w| \leq 0.01 \mathrm{~m} / \mathrm{s})$ in the ECMWF trajectories.

area of about $300 \mathrm{~km} \times 300 \mathrm{~km}$ around Lindenberg. This leads to an uplift of moist air masses from below and to the formation of the wave-induced ISSR and the cirrus cloud.

\section{Ice supersaturation on isobaric surfaces}

In order to visualise the horizontal extension of the studied ice-supersaturated region we employ the technique that we have introduced in Case 1. We do this both for the icesupersaturated region that the radiosonde detected at $0 \mathrm{~h}$ and, additionally, for the humid layer with the extended thin cirrus just below the tropopause.

In the present case (Fig. 11), the ECMWF model underestimated the relative humidity by a large amount, it had $R H i=92 \%$ where the radiosonde gave values in excess of $120 \%$. Hence, even ECMWF $R H i$-values as low as $70 \%$ may actually have been supersaturated. Aside from the ISSR over Lindenberg, the map, representing the ECMWF model level 36 (i.e. pressure surface $p=389 \mathrm{hPa}$ ), shows other moist regions which are independent of the one over Lindenberg and which generally last for longer times. As these ice-supersaturated regions were situated 100 to $200 \mathrm{hPa}$ below the tropopause, there is no apparent correlation between their boundaries and the isolines of potential vorticity ( $P V=1.6,2.5,3.5 \mathrm{PV}$ units, PVU). Again, as in Case 1 we find in a plot $\log ($ area $)$ vs. $\log$ (perimeter) a slope of less than 2 , that is, a signature for the fractal geometry of the ISSRs.

An analogous calculation is performed for the tropopause cirrus, for which we investigate the humidity field and its gradients on the model level 30 ( $t=-6 \mathrm{~h}, p=202$ and $t=0 \mathrm{~h}$, 


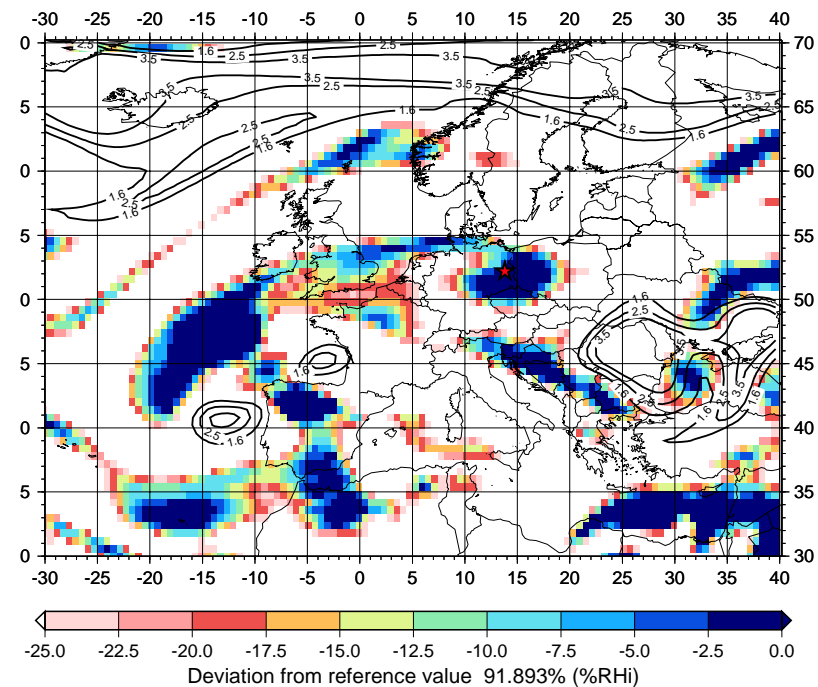

Fig. 11. Visualisation of the ice supersaturated region measured by the radiosonde at 21 March 2000, 00:00 UTC on ECMWF model level $36(p=389 \mathrm{hPa})$, together with other moist regions. The reference value of $\mathrm{RHi}$ has been taken from the comparison of the radiosonde and ECMWF data at $t=0 \mathrm{~h}$. The position of Lindenberg $\left(14.12^{\circ} \mathrm{E} / 52.22^{\circ} \mathrm{N}\right)$ is marked by a red star. Black contours outline potential vorticities of $1.6,2.5$, and 3.5 PVU.

$p=204 \mathrm{hPa}$ ). The horizontal extensions of the (likely) supersaturated regions are shown in Fig. 12. During the time interval between $t=-6 \mathrm{~h}$ and $t=+12 \mathrm{~h}$ (data at $t=+6 \mathrm{~h}$ and $t=+12 \mathrm{~h}$ not shown) an ice supersaturated layer can be seen over Germany, which is slowly disappearing. The boundary of this ISSR is closely followed by the PV-contours, reflecting the situation of this region just below the tropopause. There is a good qualitative agreement between the position of the ice supersaturated layer obtained from the ECMWF data (Fig. 12) and the faint cirrus cloud in the AVHRR infrared image (Fig. 5): The existence of a thin cirrus cloud in the time period $t=-6 \mathrm{~h}$ until $t=6 \mathrm{~h}$ can be supported by the ECMWF analyses.

\section{Conclusions}

In this case study we have analysed the formation and evolution of an ice-supersaturated region that has been detected by a radiosonde over Lindenberg on 21 March 2000, 00:00 UTC. The sonde reported supersaturation in the pressure range $320 \leq p \leq 408 \mathrm{hPa}$. We have analysed this case using satellite data (METEOSAT IR imagery and AVHRR data), simple radiative transfer calculations, trajectory calculations based on operational ECMWF analyses, and mesoscale numerical simulations.

We found that in this case the generation of supersaturation was due to a lifting of airmasses by about 20 to $40 \mathrm{hPa}$ that was caused by a superposition of two packets of gravity
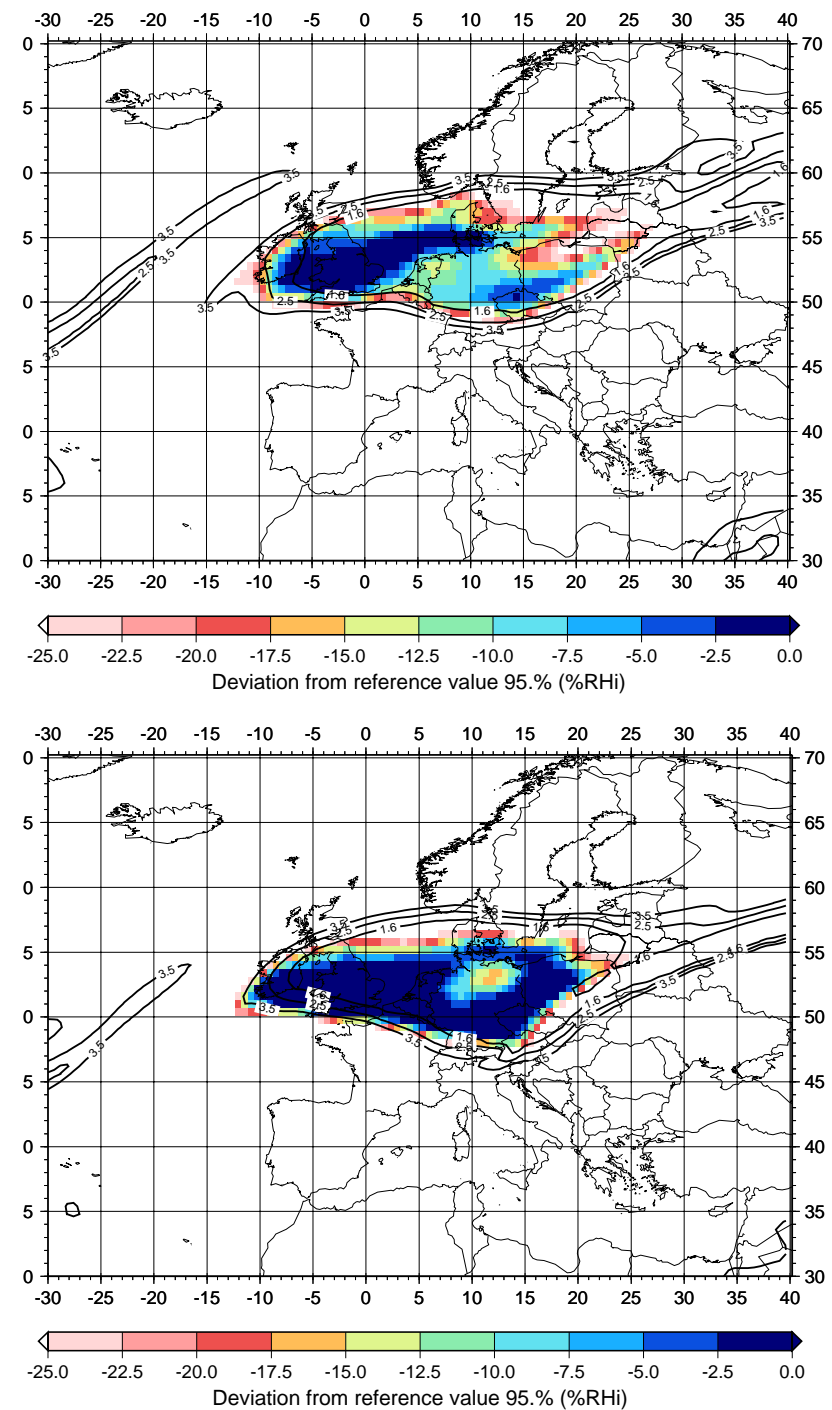

Fig. 12. Evolution of the cirrus cloud situated on ECMWF model level 30 at $t=-6 \mathrm{~h}, p=204 \mathrm{hPa}$ (top) and $t=0 \mathrm{~h}, p=202 \mathrm{hPa}$ (bottom). The reference value of $R H i$ is set to $R H i=95.0 \%$. Black contours outline potential vorticities of 1.6, 2.5, and 3.5 PVU.

waves, one generated by air flow past the Erzgebirge, Riesengebirge and the other excited by inertial instability on the north-eastern edge of an anticyclone. This lifting implied upward moisture transport that led to a strong increase of specific humidity (by factors 1.5 to 1.75 ) on isobaric surfaces, while the temperature decreased modestly. The generated wave-induced ISSR lasted only for about half a day and vanished with the decaying wave activity. The ISSR had a vertical extension of about $2 \mathrm{~km}$, which is almost 4 times the average thickness of ice supersaturation layers found in the Lindenberg radiosonde profiles (about $500 \mathrm{~m}$, see Spichtinger et al., 2003a). Over Lindenberg, the lifting of the air not only led to supersaturation, but also triggered the formation of a cirrus cloud that became optically thick within about 
$2 \mathrm{~h}$. The whole region around Lindenberg was covered by another, still higher and more long-lasting, optically thin cirrus just below the tropopause where the radiosonde reported high relative humidities with respect to ice, yet below $100 \%$.

As in our previous paper (Case 1) we can ask what caused the supersaturation. The answer depends on the point of view of the observer: From an Eulerian point of view (i.e. fixed location) supersaturation was caused by moisture transport from below, whereas the temperature was nearly constant. However, from a Lagrangian point of view (i.e. moving with the air-parcels along the mesoscale trajectories) it was adiabatic cooling that led to supersaturation. It is very important, though not always easy, to distinguish between these two point of views. In the present case, the ECMWF trajectories represent a quasi Eulerian point of view, that is, the horizontal motion is represented quite correctly but the vertical motion is not; from $t=-6 \mathrm{~h}$ to $t=+6 \mathrm{~h}$ the trajectories were nearly isobaric. But the mesoscale trajectories showed the (correct) Lagrangian point of view.

Whereas in Case 1 the lifetime of the supersaturated region exceeds a day (more precisely one should say that the tracked air parcels were part of the ISSR for more than a day, the ISSR itself lasted considerably longer), in the present case it was only about half a day. Whether this is systematic, that is, whether supersaturation generated by small scale vertical air motion lasts on average shorter than supersaturation generated by large scale ascents is not known.

We also have seen that the considered ISSR appeared over a larger area where other ISSRs were already present and which also still were around when our ISSR was already disappearing. Unfortunately, we had to use recalculated humidity fields to visualise the ISSRs because the ECMWF model itself does not allow supersaturation. This is something that should be improved, and we are currently working on an improved cloud scheme in the ECMWF model that allows icesupersaturation in the upper troposphere to exist. We hope that inclusion of ISSRs in large scale models will contribute to an improvement of the representation of cirrus clouds and their radiative properties. This would be of great value for weather forecasts and for studies of climate change. Furthermore, we are going to conduct mesoscale numerical simulations of the upper troposphere in order to study the formation and evolution of ice-supersaturated regions together with their embedded cirrus clouds in more detail.

\section{Appendix}

In Case 1 we analysed how relative humidity changes along a trajectory due to the respective changes in temperature, specific humidity, and pressure:

$d R H i=\frac{\partial R H i}{\partial T} d T+\frac{\partial R H i}{\partial q} d q+\frac{\partial R H i}{\partial p} d p$.

While the temperature contribution dominated for Case 1, the ECMWF based trajectories for the present case suggest that the moisture term dominates. Dominance of the moisture term can be due to either cloud processes that change $q$ or due to unresolved motions, i.e. failure of the ECMWF trajectory calculation because the time interval between the individual analyses times is too long to resolve the true motion of the air parcels. Let us analyse this a bit further.

For this analysis it is better to use the (extensive quantity) water vapour partial density $\rho_{v}$ instead of (the intensive quantity) $q\left(q=\rho_{v} / \rho\right.$ with air density $\left.\rho\right)$. Then we write:

$$
\frac{d R H i}{d t}=\frac{\partial R H i}{\partial T} \frac{d T}{d t}+\frac{\partial R H i}{\partial \rho_{v}} \frac{d \rho_{v}}{d t} .
$$

The total derivative $d \rho_{v} / d t$ can be rewritten in the following way:

$$
\begin{aligned}
\frac{d \rho_{v}}{d t} & =\frac{\partial \rho_{v}}{\partial t}+(\mathbf{v} \cdot \nabla) \rho_{v} \\
& =\frac{\partial \rho_{v}}{\partial t}+\nabla \cdot\left(\mathbf{v} \rho_{v}\right)-\rho_{v} \nabla \cdot \mathbf{v} \\
& =Q-\rho_{v} \nabla \cdot \mathbf{v} .
\end{aligned}
$$

For $\rho_{v}$ the continuity equation holds, and only when there are cloud processes or chemical processes involving water molecules, the source term $Q$ is different from zero.

The budget equation along a trajectory is now:

$$
\frac{d R H i}{d t}=\frac{\partial R H i}{\partial T} \frac{d T}{d t}+\frac{\partial R H i}{\partial \rho_{v}}\left(Q-\rho_{v} \nabla \cdot \mathbf{v}\right) .
$$

We could now re-introduce the specific humidity and would arrive at a similar equation with $q$ replacing $\rho_{v}$ (and with an accordingly re-defined source term $Q^{\prime}$ and term involving the pressure re-included).

Often, the atmosphere can be regarded as an incompressible medium, such that $\nabla \cdot \mathbf{v}=0$. This means that, unless there is a non-vanishing source term $Q$ (e.g. cloud formation), the contribution of the moisture term to the evolution of the relative humidity along a Lagrangian trajectory should vanish (see also Stohl and Seibert, 1998). The large $q$-change along the trajectories based on 6 hourly ECMWF analyses indicates a failure in determining parcel properties along the trajectory.

Acknowledgements. We thank R. Meyer and R. Büll for processing and providing the METEOSAT data and $\mathrm{H}$. Wernli for providing the model LAGRANTO and for some fruitful discussions. The mesoscale numerical simulations were performed on the NEC SX6 computer at the German High Performance Computing Center for Climate and Earth System Research in Hamburg, Germany. The analysis data were kindly provided by ECMWF for the special project "Ice supersaturation and cirrus clouds". This article contributes to COST action 723 (Data exploitation and modeling for the upper troposphere and lower stratosphere) and to the DLR/HGF-project "Particles and Cirrus Clouds" (PAZI-2).

Edited by: W. Lahoz 


\section{References}

Dörnbrack, A., Leutbecher, M., Kivi, R., and Kyr, E.: Mountain wave induced record low stratospheric temperatures above Northern Scandinavia, Tellus, 51A, 951-963, 1999.

Dörnbrack, A., Birner, T., Fix, A., Flentje, H., Meister, A., Schmid, H., Browell, E. V., and Mahoney, M. J.: Evidence for inertia gravity waves forming polar stratospheric clouds over Scandinavia, J. Geophys. Res., 107(D20), 8287, doi:10.1029/2001JD000452, 2002.

Dudhia, J.: A non-hydrostatic version of the Penn State-NCAR Mesoscale Model: Validation tests and simulation of an Atlantic cyclone and cold front, Mon. Wea. Rev., 121, 1493-1513, 1993.

Dudhia, J., Gill, D., Guo, Y.-R., Manning, K., and Wang, W.: PSU/NCAR Mesoscale Modeling System Tutorial Class Notes and User Guide: MM5 Modeling System Version 3, 2001, available at http://www.mmm.ucar.edu/mm5/documents/MM5_ tut_Web_notes/TutTOC.html.

Ebert, E. E. and Curry, J. A.: A parameterization of cirrus cloud optical properties for climate models, J. Geophys. Res., 97, 38313836, 1992.

Gierens, K., Schumann, U., Helten, M., Smit, H. G. J., and Marenco, A.: A distribution law for relative humidity in the upper troposphere and lower stratosphere derived from three years of MOZAIC measurements, Ann. Geophys., 17, 1218-1226, 1999 ,

SRef-ID: 1432-0576/ag/1999-17-1218

Gill, A. E.: Atmosphere-Ocean Dynamics, Academic Press New York, 1982.

Grell, G. A., Dudhia, J., and Stauffer, D. R.: A description of the fifth-generation Penn State/NCAR mesoscale model (MM5), NCAR Technical Note, NCAR/TN-398+STR, 117, 1994.

Hong, S.-Y. and Pan, H.-L.: Nonlocal boundary layer vertical diffusion in a medium-range forecast model, Mon. Wea. Rev., 124, 2322-2339, 1996.

Knox, J. A.: Possible mechanism of clear-air turbulence in strongly anticyclonic flow, Mon. Wea. Rev., 125, 1251-1259, 1997.

Nagel, D., Leiterer, U., Dier, H., Kats, A. Reichard, J., and Behrendt, A.: High accuracy humidity measurements using the standardized frequency method with a research upper-air sounding system, Meteorol. Z., 10, 395-405, 2001.

Peters, D. and Waugh, D. W.: Influence of barotropic shear on the poleward advection of upper-troposheric air, J. Atmos. Sci., 53, 3013-3031, 1996.
Peters, D., Hoffmann, P., and Alpers, M.: On the appearance of inertia gravity waves on the north-easterly side of an anticyclone, Meteorol. Z., 12, 25-35, 2003.

Plougonven, R., Teitelbaum, H., and Zeitlin, V.: Inertia gravity wave generation by the tropospheric midlatitude jet as given by the Fronts and Atlantic Storm-Track Experiment radio soundings, J. Geophys. Res., 108, 4686, doi:10.1029/2003JD003535, 2003.

Reisner, J., Rasmussen, R. J., and Bruintjes, R. T.: Explicit forecasting of supercooled liquid water in winter storms using the MM5 mesoscale model, Q. J. Roy. Meteorol. Soc., 124B, 1071-1107, 1998.

Schumann, U.: Contrail Cirrus, in: Cirrus, edited by: Lynch, D. K., Sassen, K., Starr, D. O'C., and Stephens, G., Oxford University press, Oxford, UK, 231-255, 2002.

Spichtinger, P., Gierens, K., Leiterer, U., and Dier, H.: Ice supersaturation in the tropopause region over Lindenberg, Germany, Meteorol. Z., 12, 143-156, 2003a.

Spichtinger, P., Gierens, K., and Read, W.: The global distribution of ice-supersaturated regions as seen by the microwave limb sounder, Q. J. Roy. Meteorol. Soc., 129, 3391-3410, 2003 b.

Spichtinger, P., Gierens, K., and Wernli, H.: A case study of the formation and evolution of ice supersaturation in the vicinity of a warm conveyor belt's outflow region, Atmos. Chem. Phys., 5, 973-987, 2005. (Case 1),

SRef-ID: 1680-7324/acp/2005-5-973

Stohl, A. and Seibert, P.: Accuracy of trajectories as determined from the conservation of meteorological tracers, Q. J. Roy. Meteorol. Soc., 124, 1465-1484, 1998.

Thompson, R. O. R. Y.: Observation of inertial gravity waves in the stratosphere, Q. J. Roy. Meteorol. Soc., 104, 691-698, 1978.

Wernli, H. and Davies, H. C.: A Lagrangian-based analysis of extrtropical cyclones, I: The method and some applications, Q. J. Roy. Meteorol. Soc., 123, 467-489, 1997.

Zhang, F.: Generation of Mesoscale Gravity Waves in UpperTropospheric Jet-Front Systems, J. Atmos. Sci., 61, 440-457, 2004.

Zhang, F., Wang, S., and Plougonven, R.: Uncertainties in using the hodograph method to retrieve gravity characteristics from individual soundings, Geophys. Res. Lett., 31, L11110, doi:10.1029/2004GL019841, 2004. 